\title{
Air Pollution and Cardiovascular Hospital Admissions in Kerman, Iran
}

\author{
Hashemi S. Yaser ${ }^{1}$, Khanjani Narges ${ }^{2,3^{*}}$
}

\begin{abstract}
${ }^{1}$ Department of Environmental Health Engineering, School of Public Health, Tehran University of Medical Sciences, Tehran, Iran. ${ }^{2}$ Associate Professor, Environmental Health Research Center, Faculty of Public Health, Kerman University of Medical Sciences, Kerman, Iran. ${ }^{3}$ Honorary Research Fellow, Monash Centre for Occupational \& Environmental Health, School of Public Health and Preventive Medicine, Monash University, Melbourne, Australia
\end{abstract}

"Corresponding Author: Narges Khanjani, Associate Professor, Department of Epidemiology and Biostatistics, School of Public Health, Kerman University of Medical Sciences, Kerman, Iran, Tel/Fax: 034-3132-5102; Email: n_khanjani@kmu.ac.ir

\begin{abstract}
Air pollution is a human health risk factor. Cardiovascular disease incidents may be related to air pollution. In this study, the relation between cardiovascular disease hospital admissions and ambient air pollutants has been studied in Kerman, Iran. Data about cardiovascular emergency admissions was inquired from a major referral hospital and air pollution data was inquired from the Kerman Environmental Protection Agency from March 2006 to March 2014. The concentration of seven ambient air pollutants $\left(\mathrm{SO}_{2}, \mathrm{NO}_{2}, \mathrm{O}_{3}, \mathrm{CO}, \mathrm{PM}_{10}, \mathrm{NO}_{\mathrm{X}}\right.$ and $\left.\mathrm{NO}\right)$ is measured daily in Kerman. The relation between hospital admissions for cardiovascular disease and air pollution was analyzed by using negative binomial regression. Significant correlations between ozone and hospital admissions for cardiovascular disease in women $(r=0.38)$, men $(r$ $=0.24)$ and in total $(\mathrm{r}=0.35)$ were observed and as ozone concentration increased the number of admissions increased as well. In both crude and adjusted negative binomial regression, increase in ozone concentration was significantly associated with increased hospital admissions for cardiovascular disease. There was not a significant relation between other air pollutants and cardiovascular admissions. It seems like increase in ozone concentration is associated with increased hospital admissions for cardiovascular diseases in Kerman.
\end{abstract}

Keywords: Air pollution; Cardiovascular admissions; Ozone; Kerman
Received date: December 30, 2015

Accepted date: May 02, 2016

Published date: May 05, 2016

Citation: Khanjani, N., et al. Air Pollution and Cardiovascular Hospital Admissions in Kerman, Iran. (2016) J Heart Cardiol 2(1): 22-27.

DOI: $10.15436 / 2378-6914.16 .018$

\section{Introduction}

Uncontrolled urban expansion along with rapid economic development and increased energy consumption has caused numerous environmental problems for humans ${ }^{[1,2]}$. In the recent years, human's activities have made alarming changes in ambient air pollutants that lead to climate change and serious health consequences ${ }^{[3]}$. Air pollution is nowadays the most critical environmental challenge and can increase cardiovascular, respiratory and many more diseases ${ }^{[4]}$. The adverse effect of air pollution on cardiovascular health has been shown in a number of large and epidemiological studies. Some studies have suggested that even short exposure to air pollution is associated with a significant increase in the risk of cardiovascular disease and death from myocardial ischemia, arrhythmia, and heart failure ${ }^{[4,5]}$.

Several studies have suggested that air pollutants at the levels currently measured in developed and developing countries have adverse effects on human health and there are concerns that air pollution may become a serious threat for public health in the coming years ${ }^{[6,7]}$. Based on the World Health Organization's report, at the beginning of the $21^{\text {th }}$ century more than 200 million people in the world were exposed to air pollutant concentrations higher than air quality standards ${ }^{[1]}$.

The World Health Organization estimates that air pollution is responsible for 3 million premature deaths per year ${ }^{[5]}$. The increased risk of death associated with air pollution is probably due to increase in respiratory and cardiovascular mortality ${ }^{[8,9]}$. This

Copyrights: (C) 2016 Khanjani, N. This is an Open access article distributed under the terms of Creative Commons Attribution 4.0 International License. 
relation is particularly important for low-income or middle-income countries with rapid economic development, which the concentrations of air pollutants are raising ${ }^{[9,10]}$. A report from the United Nations Environmental Program stated many developing countries in Latin America and Asia have alarming levels of air pollution. The environmental performance indicators report in 2006 showed that among 133 countries Iran is ranked $117^{\text {th }}$ in the air quality index table. According to the World Bank's report in 2005 the annual loss of air pollution in Iran was 14420 billion Rials equivalent to 1.6\% of Gross Domestic Product (GDP) ${ }^{[11]}$.

In developing countries, strict environmental legislation has partially led to air pollution control, but due to changes in life styles from traditional to industrial and lack of appropriate control on pollutant resources, air pollution has had an ascending trend in recent years. One of these countries is Iran in which three of its cities are among the most polluted cities in the world based on the 2011 WHO report ${ }^{[1]}$.

Several studies conducted in Europe and America have shown that air pollution is associated with cardiovascular and respiratory deaths and hospital admissions. Although more studies have focused on the respiratory system as the main target of air pollution adverse effects, but recent evidence has shown that air pollution can also affect the cardiovascular system and particularly lead to ischemic heart diseases ${ }^{[12-14]}$.

The harmful effects of increasing concentrations of particulate matter (PM) and carbon monoxide and other pollutants has been demonstrated as an increase in hospital emergency admissions for respiratory diseases in several studies ${ }^{[15]}$. In addition, some studies conducted in the United States ${ }^{[16,17]}$, Canada ${ }^{[18,19]}$ and Europe ${ }^{[20,21]}$ have shown a significant relation between cardiovascular and respiratory diseases hospital admissions and air pollution. These results show that air pollution is not only a risk factor for respiratory diseases but also for acute cardiac events such as acute coronary syndrome and heart attack ${ }^{[14,22]}$. The air pollution standards for calculating air quality index (AQI) has been presented in Table $1^{[23]}$. According to Air Quality Index, values of 0-50 is good, 51-100 is moderate, 101-150 is unhealthy for sensitive groups, 151-200 is unhealthy, 201-300 is very unhealthy and more than 300 value is hazardous.

Table 1: Air pollutant Standards for estimating AQI (Air Quality Index)

\begin{tabular}{|c|c|c|c|c|c|c|c|}
\hline & AQI values & $\begin{array}{l}\mathrm{NO}_{2} \\
\text { (ppm) } \\
1 \text { hour }\end{array}$ & $\begin{array}{l}\mathrm{SO}_{2} \\
(\mathrm{ppm}) \\
24 \text { hours }\end{array}$ & $\begin{array}{l}\text { CO } \\
(\mathrm{ppm}) \\
8 \text { hours }\end{array}$ & $\begin{array}{l}\mathbf{P M}_{10} \\
\left(\mu \mathrm{g} / \mathrm{m}^{3}\right) \\
24 \text { hours }\end{array}$ & $\begin{array}{l}O_{3} \\
\text { (ppm) } \\
1 \text { hour }\end{array}$ & $\begin{array}{l}O_{3} \\
\text { (ppm) } \\
8 \text { hour }\end{array}$ \\
\hline Good & $0-50$ & $0-0.053$ & $0-0.034$ & $0-4.4$ & $0-54$ & - & $0-0.059$ \\
\hline Moderate & $51-100$ & $0.054-0.1$ & $0.035-0.144$ & $4.5-9.4$ & $55-154$ & - & $0.060-0.075$ \\
\hline $\begin{array}{l}\text { Unhealthy } \\
\text { for sensitive }\end{array}$ & $101-150$ & $0.101-0.360$ & $0.145-0.224$ & $9.5-12.4$ & $155-254$ & $0.125-0.164$ & $0.076-0.095$ \\
\hline Unhealthy & $151-200$ & $0.361-0.640$ & $0.225-0.304$ & $12.5-15.4$ & $255-354$ & $0.165-0.204$ & $0.096-0.115$ \\
\hline $\begin{array}{l}\text { Very } \\
\text { unhealthy }\end{array}$ & $201-300$ & $0.641-1.24$ & $0.305-0.604$ & $15.5-30.4$ & $355-424$ & $0.205-0.404$ & $0.116-0.374$ \\
\hline \multirow{2}{*}{ Hazardous } & $301-400$ & $1.25-1.64$ & $0.605-0.804$ & $30.5-40.4$ & $425-504$ & $0.405-0.504$ & - \\
\hline & $401-500$ & $1.65-2.04$ & $0.805-1.004$ & $40.5-50.4$ & $505-604$ & $0.505-0.604$ & - \\
\hline
\end{tabular}

Kerman is located in the southeast of the Central Iran Plateau, 1756 meters above sea level. It's mean annual temperature is $15.8^{\circ} \mathrm{C}$, and average annual rainfall is $155 \mathrm{~mm}$. Kerman's area is about 14000 hectares and is categorized as one of Iran's metropolises due to it's area and population. According to the last census in 2011, this city has a population of more than 534,441 people ${ }^{[1]}$. The sources of air pollution in this city are different industries, and factories, the increased number of cars and transportation vehicles, and dust originating from deserts around the city ${ }^{[24]}$.

In this research, the number of cardiovascular disease hospital admission and the corresponding concentrations of some air pollutants in Kerman were studied.

\section{Materials and Methods}

This study was an ecological study based on recorded data from Kerman city, Iran. The number of cardiovascular disease admissions per day since March 2006 until March 2014 was inquired from Afzalipour Hospital and Be'esat Clinic. Afzalipour Hospital and Be'esat Clinic are two referral centers and the main university affiliated hospital and clinic in Kerman Province.

Data related to air pollution was inquired from the Kerman Environmental Protection Agency for the same time frame. The concentration of 7 pollutants including $\mathrm{SO}_{2}, \mathrm{NO}_{2}, \mathrm{O}_{3}, \mathrm{CO}, \mathrm{PM}_{10}, \mathrm{NO}_{\mathrm{X}}$, and $\mathrm{NO}$ are measured daily in Kerman by a fixed station. The urban monitoring stations in Kerman uses the Beta-ray absorption method for measuring the concentration of PM ${ }_{10}$, UV fluorescence for $\mathrm{SO}_{2}$, chemical luminance for $\mathrm{NO}, \mathrm{NO}_{2}$ and $\mathrm{NO}_{\mathrm{X}}$, non-diffraction infrared absorption (NDIR) for $\mathrm{CO}$ and $\mathrm{UV}$ absorption for measuring the concentration of $\mathrm{O}_{3}$.

In this study, the number of hospital admissions related to cardiovascular disease, including myocardial infarction, arrhythmias, heart failure, mitral valve failure and angina was determined. As the number of cases was low or even zero on many days, the number of admitted patients were determined per month and were matched with the monthly average of air pollution data.

The relationship between cardiovascular disease hospital admissions and air pollution was assessed initially through Pear- 
son correlation, but due to lack of fitness, negative binomial regression was used. Crude and adjusted (for other pollutants, temperature and humidity) negative binomial regression analysis were done for each pollutant separately. In this model the count of hospital cardiac admissions was the dependent and the air pollutants were the predicting variables. The results of crude and adjusted negative binomial regression show the effect of each pollutant on cardiovascular visits as ratio of increase in visits in month per unit increase $\left(\mathrm{ppm}\right.$ or $\left.\mathrm{ug} / \mathrm{m}^{3}\right)$ in pollutants monthly average. For some pollutants $\left(\mathrm{NO}_{2}, \mathrm{NOx}, \mathrm{O}_{3}, \mathrm{SO}_{2}\right)$ this increase was calculated per 1000-unit increase, as the range of the variable was too small. All statistical analysis was done using SPSS 21.

\section{Results}

In this study during eight years, 1375 patients including 690 women and 685 men were referred to the emergency department or clinic. The daily average, standard deviation, minimum and maximum of 7 air pollutants during this time in Kerman has been presented in Table 2 .

Table 2: Status of air pollutants in Kerman from March 2006 to March 2014

\begin{tabular}{|l|c|c|c|c|}
\hline Pollutant & Mean & SD & Minimum & Maximum \\
\hline CO $(\mathbf{p p m})$ & 1.217 & 0.829 & 0.001 & 3.931 \\
\hline PM $_{\mathbf{1 0}}\left(\mathbf{u g} / \mathbf{m}^{\mathbf{3}}\right)$ & 115.478 & 90.835 & 32.600 & 663.400 \\
\hline NO $(\mathbf{p p m})$ & 0.175 & 0.925 & 0.001 & 6.009 \\
\hline NO $\mathbf{( p p m )}$ & 0.018 & 0.008 & 0.002 & 0.050 \\
\hline NO $\mathbf{( p p m )}$ & 0.033 & 0.017 & 0.013 & 0.118 \\
\hline $\mathbf{O}_{\mathbf{3}}(\mathbf{p p m})$ & 0.025 & 0.013 & 0.006 & 0.063 \\
\hline SO $\mathbf{( p p m )}$ & 0.011 & 0.016 & 0.001 & 0.147 \\
\hline
\end{tabular}

A significant positive relation was observed in correlation analysis between number of cardiovascular diseases admissions per month and ambient air ozone levels so that with increased levels of ozone, hospital admissions for both men and women increased. In some pollutants a reverse significant relation was seen that seems to be a chance finding. (Table 3)

Table 3: The correlations between cardiovascular patient visits and air pollutants and their p-value.

\begin{tabular}{|l|c|c|c|}
\hline Pollutant & Male & Female & Total \\
\hline CO & -0.269 & -0.393 & -0.38 \\
& $\mathrm{P}=0.020$ & $\mathrm{P}=0.0002$ & $\mathrm{P}=0.0003$ \\
\hline PM & -0.253 & -0.321 & -0.327 \\
\hline NO & $\mathrm{P}=0.0204$ & $\mathrm{P}=0.0029$ & -0.0024 \\
\hline NO & 0.059 & -0.096 & -0.027 \\
\hline NOx & $\mathrm{P}=0.594$ & -0.4804 & -0.397 \\
\hline O & -0.282 & $\mathrm{P}=0.0001$ & $\mathrm{P}=0.0002$ \\
\hline SO & -0.075 & -0.076 & -0.086 \\
\hline
\end{tabular}

Also in crude and adjusted negative binomial analysis significant relations between increased levels of ozone and cardiovascular disease visits were observed. None of the other contaminants showed a significant relation in the adjusted model. (Table 4) 
Table 4: Results of crude and adjusted negative binomial regression and the effect of each pollutant on cardiovascular visits (ratio of increase in visits in month per unit increase in pollutants monthly average)

\begin{tabular}{|c|c|c|c|c|c|c|c|}
\hline $\begin{array}{l}\text { Respiratory } \\
\text { deaths }\end{array}$ & Pollutant & $\begin{array}{l}\text { Crude } \\
\text { IRR }\end{array}$ & P-value & Crude $[95 \%$ CI] & $\begin{array}{l}\text { Adjusted } \\
\text { IRR }\end{array}$ & P-value & Adjusted[95\% CI] \\
\hline \multirow{7}{*}{ Total } & $\mathrm{CO}$ & 0.87467 & $<0.001$ & $(0.81538,0.93828)$ & 0.89546 & 0.055 & $(0.79978,1.00257)$ \\
\hline & $\mathrm{PM}_{10}$ & 0.99893 & 0.002 & $(0.99827,0.99959)$ & 0.99982 & 0.640 & $(0.99906,1.00058)$ \\
\hline & NO & 0.99125 & 0.804 & $(0.92463,1.06267)$ & 0.97420 & 0.444 & $(0.91115,1.04161)$ \\
\hline & $\mathrm{NO}_{2} *$ & 0.98673 & $<0.001$ & $(0.98004,0.99345)$ & 0.99430 & 0.268 & $(0.98429,1.00441)$ \\
\hline & NOx * & 0.99850 & 0.431 & $(0.99480,1.00223)$ & 1.00342 & 0.143 & $(0.99885,1.00802)$ \\
\hline & $\mathrm{O}_{3}^{*}$ & 1.00859 & 0.001 & $(1.00362,1.01358)$ & 1.00618 & 0.037 & $(1.00038,1.01200)$ \\
\hline & $\mathrm{SO}_{2} *$ & 1.00325 & 0.129 & $(0.99906,1.00746)$ & 1.00292 & 0.129 & $(0.99915,1.00671)$ \\
\hline \multirow{7}{*}{ Male } & $\mathrm{CO}$ & 0.90117 & 0.010 & $(0.83255,0.97544)$ & 0.92717 & 0.257 & $(0.81358,1.05662)$ \\
\hline & $\mathrm{PM}_{10}$ & 0.99907 & 0.016 & $(0.99831,0.99982)$ & 0.99978 & 0.633 & $(0.99887,1.00069)$ \\
\hline & $\mathrm{NO}$ & 1.02007 & 0.598 & $(0.94740,1.09832)$ & 1.01082 & 0.783 & $(0.93645,1.09109)$ \\
\hline & $\mathrm{NO}_{2} *$ & 0.98925 & 0.007 & $(0.98152,0.99703)$ & 0.99524 & 0.425 & $(0.98365,1.00698)$ \\
\hline & NOx * & 0.99853 & 0.485 & $(0.99442,1.00266)$ & 1.00213 & 0.437 & $(0.99676,1.00753)$ \\
\hline & $\mathrm{O}_{3} *$ & 1.00637 & 0.023 & $(1.00088,1.01189)$ & 1.00487 & 0.156 & $(0.99814,1.01164)$ \\
\hline & $\mathrm{SO}_{2} *$ & 1.00278 & 0.212 & $(0.99842,1.00716)$ & 1.00269 & 0.220 & $(0.99840,1.00700)$ \\
\hline \multirow{7}{*}{ Female } & $\mathrm{CO}$ & 0.84564 & $<0.001$ & $(0.77729,0.91999)$ & 0.85955 & 0.029 & $(0.75054,0.98440)$ \\
\hline & $\mathrm{PM}_{10}$ & 0.99872 & 0.002 & $(0.99792,0.99953)$ & 0.99984 & 0.735 & $(0.99894,1.00075)$ \\
\hline & $\mathrm{NO}$ & 0.96039 & 0.349 & $(0.88242,1.04524)$ & 0.93824 & 0.116 & $(0.86652,1.01589)$ \\
\hline & $\mathrm{NO}_{2} *$ & 0.98380 & $<0.001$ & $(0.97580,0.99186)$ & 0.99314 & 0.248 & $(0.98162,1.00480)$ \\
\hline & NOx * & 0.99846 & 0.493 & $(0.99406,1.00287)$ & 1.00482 & 0.080 & $(0.99943,1.01024)$ \\
\hline & $\mathrm{O}_{3}^{*}$ & 1.01061 & $<0.001$ & $(1.00479,1.01645)$ & 1.00721 & 0.035 & $(1.00051,1.01396)$ \\
\hline & $\mathrm{SO}_{2} *$ & 1.00364 & 0.145 & $(0.99875,1.00854)$ & 1.00303 & 0.158 & $(0.99882,1.00726)$ \\
\hline
\end{tabular}

* By each 1000 unit increase

\section{Discussion}

The present study was based on eight years of air pollution and cardiovascular patient admission data in referral centers of Kerman, Iran. In this study a significant relation was seen between ozone and cardiovascular disease admissions in emergency rooms.

Ozone is an air pollutant and a powerful oxidizing agent with high reactivity. The high chemical activity of ozone can cause health problems such as lung tissue damage and decreased lung functional capacity and heart sensitization. The existence of ozone in air can probably cause adverse health effects in the elderly, children and patients with cardiovascular and respiratory disease. Troposphere ozone is a pollutant that mainly enters human body through respiration. This gas causes respiratory complications (reduced lung capacity, asthma, and nasal congestion), eye burning sensation, and failure of immune defense against infectious diseases ${ }^{[25]}$.

Ground level ozone is created by chemical reactions between oxides of nitrogen (NOx) and volatile organic compounds (VOCs). Ozone is likely to reach unhealthy levels on hot sunny days in urban environments ${ }^{[26]}$. Kerman is a city with desert climate and does enjoy plenty of sunlight during the year ${ }^{[27]}$. This fact may partly explain the high levels of ambient ozone in Kerman.

In the present study $\mathrm{SO}_{2}$ did not show a significant relation to cardiovascular admissions. However, $\mathrm{SO}_{2}$ has shown significant associations with cardiovascular admissions in other studies. In Spain, a rise of $10 \mu \mathrm{g} / \mathrm{m}^{3}$ in 24 hour $\mathrm{SO}_{2}$ levels was associated with an increment of $3.0 \%(95 \%$ CI, 0.4 to $5.7 \%)$ in the expected number of cardiovascular admissions ${ }^{[20]}$.

Some epidemiological studies have been conducted on the relationship between air pollution and cardiovascular disease such as a study performed by Barchielli et al in 2011 in Italy that estimated the correlation between air pollutants $\left(\mathrm{CO}, \mathrm{NO}_{2}\right.$ and $\mathrm{PM}_{10}$ ) with cardiovascular mortality and acute myocardial infarction hospital admissions. In this study the elderly, women and patients with a history of chronic lung disease and blood pressure were at higher risk and increase in the level of pollutants was associated with increased referrals of acute myocardial infarction patients to hospitals ${ }^{[28]}$.

Another study done by Michelle et al in 2009 in America investigated the chemical composition of fine particulate matter $\left(\mathrm{PM}_{2.5}\right)$ and the effects of these particles on health and cardiovascular hospital admissions and showed that whenever the composition of particulate nickel, vanadium and carbon compounds in ambient air increased, cardiovascular hospital admissions increased as well[ ${ }^{[29]}$.

Yorifuji et al in 2014 in Japan studied the effects of air pollution on cardiovascular patients and their hospital referral and found particulate matter exposure increases the risks of onset of cardiovascular and cerebrovascular disease (including hemorrhagic stroke) shortly after exposure ${ }^{[30]}$. Dominici et al in 2006 in the US estimated the risks of hospital admissions associated with exposure 
to $\mathrm{PM}_{2.5}$ for Medicare enrollees and concluded that exposure to $\mathrm{PM}_{25}$ in short-term increases the risk of hospital admission for cardiovascular and respiratory diseases ${ }^{[31]}$.

In the study done in 2001 in Spain, there was a significant relation in cardiovascular disease hospital admissions and concentrations of $\mathrm{SO}_{2}$, black smoke and $\mathrm{CO}$ with $\mathrm{RR}$ of 1.05, 1.038 and 1.029 respectively in summer ${ }^{[20]}$.

In another study conducted in Sydney, Australia, the numbers of emergency cardiovascular patients aged over 65 years in a five-year period were studied and a significant positive association was found between emergencies cardiovascular disease patient visits and particulate matter, carbon monoxide and nitrogen di-oxide ${ }^{[32]}$. Sunyera et al in 2003 investigated the relation between ambient air levels of sulfur dioxide $\left(\mathrm{SO}_{2}\right)$ and cardiovascular hospital admissions in seven European countries (the cities of Birmingham, London, Milan, Paris, Rome, and Stockholm, and in the Netherlands) and found that $\mathrm{SO}_{2}$ can cause ischemic cardiac events. They also mentioned that in cities with low levels of ambient air $\mathrm{SO}_{2}$ there are less cardiovascular patient admissions ${ }^{[33]}$.

Studies have also been conducted about the correlation between cardiovascular disease and air pollution in Iran. Hashemi et al assessed the relation between air pollution and cardiovascular mortality in Kerman and found a significant correlation between ozone and cardiovascular mortality in females ${ }^{[1]}$. In Tehranin 2006 when the concentration of $\mathrm{NO}_{2}$ and $\mathrm{HCs}$ increased, cardiovascular mortality increased as well[ ${ }^{[34]}$. In another study in Tehran in 2009 there was a significant correlation between the concentration of carbon monoxide and the number of deaths due to cardiovascular and respiratory diseases, heart attack and the total deaths during the study period by correlation coefficient of $0.72,0.70,0.69$ and 0.67 respectively $^{[35]}$.

In addition to environmental pollutants, climatic elements such as temperature and humidity may also be effective in the incidence of cardiovascular disease or mortality. Some studies have considered these factors, and the relationship between these factors and mortality has been calculated ${ }^{[20,27]}$. In this study, results were adjusted for temperature and humidity in multivariate (adjusted) negative binomial regression.

In these factors such as diet or life style may have affected people's cardiovascular department visits, but we did not have information about these variables, and therefore we were not able to adjust for them. This study also had the limitations of ecological studies such as cross level inference.

\section{Conclusion}

According to this study the increase in ozone $\left(\mathrm{O}_{3}\right)$ was significantly associated with an increased rate of emergency cardiovascular visits in Kerman. To investigate the effect of air pollution on cardiovascular hospital admissions, more studies in cities with more pollution is needed.

Acknowledgment: This proposal was approved by Environmental Medical Research Committee at the School of Public Health and was funded by the Deputy of Research at Kerman University of Medical Science, Kerman, Iran.

\section{References}

1. Hashemi, S.Y., Khanjani, N., Soltaninejad, Y., et al. Air pollution and cardiovascular mortality in Kerman from 2006 to 2011. (2014) American Journal of Cardiovascular Disease Research 2(2): 27-30.

2. Männistö, T., Mendola, P., Laughon, K., et al. Acute and recent air pollution exposure and cardiovascular events at lobaour and delivery. (2015) Heart 101(18): 1491-1498.

3. Qian, Y., Zhu, M., Cai, B., et al. Epidemiological evidence on association between ambient air pollution and stroke mortality. (2013) J Epidemiol Community Health 67(8): 635-640.

4. Weiden, D.M., Bushra, N., Kwon, S., et al. Cardiovascular biomarkers predict susceptibility to lung injury in World Trade Center dust-exposed firefighters. (2013) Eur Respir J 41(5): 1023-1030.

5. Mills, N.L., Donaldson, K., Hadoke, P., et al. Adverse cardiovascular effects of air pollution. (2008) Nat Clin Pract Cardiovasc Med 6(1): 36-44.

6. Samet, J.M., Dominici, F., Curriero, F., et al. Fine particulate air pollution and mortality in 20 US cities, 1987-1994. (2000) N Engl J Med 343(24): 1742-1749.

7. Silverman, R.A., Ito, K., Freese, J., et al. Association of Ambient Fine Particles with Out-of-Hospital Cardiac Arrests in New York City. (2010) Am J Epidemiol 172(8): 917-923.

8. Peng, R.D., Bell, M.L., Geyh, A.S., et al. Emergency Admissions for Cardiovascular and Respiratory Diseases and the Chemical Composition of Fine Particle Air Pollution. (2009) Environ Health Perspect 117(6): 957-963.

9. Dadbakhsh, M., Khanjani, N., Bahrampour, A. Death from Respiratory Diseases and Air Pollutants in Shiraz, Iran (20062012). (2015) Journal of Environment Pollution and Human Health 3(1): 4-11.

10. Jiunn-Horng, K., Tsai-Ching, L., Keller, J., et al. Asian dust storm events are associated with an acute increase in stroke hospitalization. (2013) J Epidemiol Community Health 67(2): 125131.

11. Mohammadi, H., Oveisi Rad, H. Evaluate the relationship between atmospheric elements and Co on mortality from respiratory diseases in people under 12 years in Tehran. (2010) Journal of Geography: 33-55.

12. Ensor, K., Raun, L., Persse, D. A Case-Crossover Analysis of Out-of-Hospital Cardiac Arrest and Air Pollution. (2013) Circulation 127(11): 1192-1199.

13. Wold, L.E., Ying, Z., Hutchinson, K.R., et al. Cardiovascular Remodeling in Response to Long-Term Exposure to Fine Particulate Matter Air Pollution. (2012) Circ Heart Fail 5(4): 452-461. 14. Mansouri, F., Khanjani, N., RanadehKalankesh, L., et al. Forecasting ambient air pollutants by time series models in Kerman, Iran. (2013) Journal of School of Public Health and Institute of Public Health Research 11(2): 75-86.

15. Ghorbani, M., Younesian, M., Fotouhi, A., et al. The case - crossover relationship between exposure to air pollution and heart attacks acute syndrome in Heart Hospital of Tehran's. (2007) Journal of Epidemiology 3(2): 53-59.

16. Schwartz, J. Air pollution and hospital admissions for the elderly in Detroit, Michigan. (1994) Am J Respir Crit Care Med 150(3): 648-655.

17. Pope, C.A., Verrier, R.L., Lovett, E.G., et al. Heart rate variability associated with particulate air pollution. (1999) Am Heart 
J 138(5 Pt 1): 890-899.

18. Delfino, R.J., Murphy-Moulton, A.M., Burnett, R.T., et al. Effects of air pollution on emergency room visits for respiratory illnesses in Montreal, Quebec. (1997) Am J Respir Crit Care Med 155(2): 568-576.

19. Burnett, R.T., Dales, R.E., Brook, J.R., et al. Association between ambient carbon monoxide levels and hospitalizations for congestive heart failure in the elderly in 10 Canadian cities. (1997) Epidemiology 8(2): 162-167.

20. Ballester, F., Tenías, J.M., Pérez-Hoyos, S. Air pollution and emergency hospital admissions for cardiovascular diseases in Valencia, Spain. (2001) J Epidemiol Community Health 55(1): 57-65.

21. Le Tertre, A., Medina, S., Samoli, E., et al. Short-term effects of particulate air pollution on cardiovascular diseases in eight European cities. (2002) J Epidemiol Community Health 56(10): 773-779.

22. Ru ckerl, R., Ibald-Mulli, A., Koenig, W., Schneider, A. Air Pollution and Markers of Inflammation and Coagulation in Patients with Coronary Heart Disease. (2006) Am J Respir Crit Care Med173(4): 432-441.

23. Arfaeinia, H., Kermani, M., Aghaei, M., et al. Comparative Investigation of Health Quality of Air in Tehran, Isfahan and Shiraz Metropolises in 2011-2012. (2014) Journal of Health in the Field 1(4): 37-44.

24. Khanjani, N., .Kalankesh, L., Mansouri, F. Air pollution and Respiratory Deaths in Kerman, Iran. (From 2006 till 2010). (2012) Iranian Journal of Epidemiology 8(3): 58-65.

25. Ghanbari Ghozikali, M., Mosaferi, M., Nadafi, K. Quantification of the health effects of exposure to ozone in tabriz by using airq model. (2014) Journal of Urmia University of Medical Sciences 25(6): 521-530.

26. https://www.epa.gov/ozone-pollution
27. Khanjani, N., Bahrampour, A. Temperature and Cardiovascular and Respiratory Mortality in desert climate. A case study from Kerman Iran. (2013) Iranian J Environ Health Sci Eng 10(1): 11 .

28. Nuvolone, D., Balzi, D., Chini, M., et al. Short-Term Association between Ambient Air Pollution and Risk of Hospitalization for Acute Myocardial Infarction: Results of the Cardiovascular Risk and Air Pollution in Tuscany (RISCAT) Study. (2011) Am J Epidemiol 174(1): 63-71.

29. Michelle, B., Ebisu, K., Peng, R.D., et al. Hospital Admissions and Chemical Composition of Fine Particle Air Pollution. (2009) Am J Respir Crit Care Med 179(12): 1115-1120.

30. Yorifuji, T., Suzuki, E., Kashima, S. Cardiovascular Emergency Hospital Visits and Hourly Changes in Air Pollution. (2014) Stroke 45(5): 1264-1268.

31. Dominici, F., Peng, R., Michelle, B., et al. Fine Particulate Air Pollution and Hospital Admission for Cardiovascular and Respiratory Diseases. (2006) JAMA 295(10): 1127-1134.

32. Jalaludin, B., Morgan, G., Lincoln, D., et al. Associations between ambient air pollution and daily emergency department attendances for cardiovascular disease in the elderly (65\&plus; years), Sydney, Australia. (2006) Journal of Exposure Science and Environmental Epidemiology 16(3): 225-237.

33. Sunyera, J., Ballester, F., Le Tertrec, A., et al. The association of daily sulfur dioxide air pollution levels with hospital admissions for cardiovascular diseases in Europe (The Aphea-II study). (2003) Eur Heart J 24(8): 752-760.

34. Mohammadi, H. Relationship between climatic factors and air pollutants in Tehran deaths from heart disease. (2006) Geographic Researches 38(58): 47-66.

35. Gholizadeh, M., Farajzadeh, M., Darand, M. The correlation between air pollution and human mortality in Tehran. (2009) Hakim Research Journal 12(2): 65-71.
Journal ISSN: 2378-6914 (online)

Journal Title: Journal of Heart and Cardiology

Short title : J Heart Cardiol
Ommega Online Publishers

Journal E-mail: cardiology@ommegaonline.com

Website: www.ommegaonline.org 